\title{
Coronary heart disease risk factors in urban bus drivers
}

\author{
PD Wang ${ }^{1 *}$ and RS $\operatorname{Lin}^{2}$ \\ ${ }^{1}$ Taipei Municipal Chronic Disease Hospital, Taipei, Taiwan; and ${ }^{2}$ College of Public Health, National Taiwan University, \\ Taipei, Taiwan
}

\begin{abstract}
The purpose of this study was to determine the risk factors for coronary heart disease (CHD) in 2297 bus drivers and skilled workers from the Taipei Municipal Bus Administrative Bureau. Data for this study were compiled from the medical records of annual physical examinations for bus drivers and skilled workers conducted at Taipei Municipal Chronic Disease Hospital during the period from July 1998 to June 1999. The results showed that, after adjustment for age, hypertension rates for bus drivers $(56.0 \%, 986 / 1361)$ were significantly greater than for skilled workers $(30.6 \%$, 164/536). All age groups demonstrated a similar difference. Significant differences were also noted in body mass index, serum cholesterol, serum triglyceride and ischemic heart disease between bus drivers and skilled workers. Among bus drivers, the prevalence of obesity was $9.6 \%$, hypercholesterolemia $34.0 \%$, hypertriglyceridemia $69.4 \%$ and ischemic heart disease $1.7 \%$. By contrast, among skilled workers, the prevalence of obesity was only $4.6 \%$, hypercholesterolemia $29.9 \%$, hypertriglyceridemia $30.6 \%$ and ischemic heart disease $0.9 \%$. These findings suggest that exposure to the occupation of driving a bus may carry an increased risk of CHD and that drivers who develop signs of cardiovascular illness should be transferred to non-driving occupations within the company. Public Health (2001) 115, 261-264.
\end{abstract}

Keywords: bus driver; coronary heart disease

\section{Introduction}

The health hazards of bus drivers are well known., ${ }^{1,2}$ Numerous studies performed in various countries on coronary heart disease (CHD) and urban bus driving over the past few decades have shown an increased risk of developing CHD. In the $1960 \mathrm{~s}$, Morris et $a l^{3}$ performed a fiveyear prospective follow-up of 667 bus drivers and bus conductors in London, and found that the incidence of CHD among bus drivers was 1.8 times that of bus conductors. Netterstrom et $a l^{4}$ in a prospective study of 1396 urban bus drivers in Copenhagen, found a standardized mortality ratio for CHD of 144 in urban bus drivers and a standardized morbidity ratio of 139 for a first episode of myocardial infarction compared to the general population of Copenhagen. Paradis et $a l,{ }^{5}$ took a historical cohort of Montreal bus drivers, compared them to the general population of greater Montreal and found only a small and nonsignificant excess of ischemic heart disease mortality in the bus drivers as a whole; however, a significant increase was found in a subgroup of drivers with less than $30 \mathrm{y}$ of employment. These findings are supported by a recent Swedish study, ${ }^{1}$ which compared data from an 11.8-y prospective follow up of Gothenburg bus drivers with data prospectively gathered from men in other occupations

*Correspondence: PD Wang, Consultant Physician, Taipei Municipal Chronic Disease Hospital, No. 530, Lin-Shan N. Road, Taipei, Taiwan.

Accepted 25 April 2001 during the same period, and found that the excess risk of CHD among middle-aged bus and tram drivers occurred independently of standard risk-factor status.

The possible increased health risk associated with urban bus driving is of importance not only to the health and safety of drivers in urban transit systems, but to the vast public which uses and interacts with these systems. However, studies published over the past two decades on the health of urban bus drivers have received relatively less attention in developing countries. Whether a consistent pattern of increased risk of CHD among urban bus drivers, when compared to employees from other occupational groups, is also present in the Taiwanese population remains unclear. This case control study sought to determine whether bus drivers in Taipei are at increased risk of CHD compared with skilled workers in the same company, and to identify the factors responsible for any increased risk of CHD.

\section{Subjects and methods}

The study population included all bus drivers and skilled workers who were employed full-time by the Taipei Municipal Bus Administrative Bureau (TMBAB). Bus drivers and skilled workers who underwent an annual physical examination during the period of July 1998 to June 1999 were eligible for recruitment into the study population. A total of 2297 bus drivers and skilled workers, representing over $96 \%$ of the target population, were examined. Data 
analysis was restricted to male drivers and skilled workers because of the small number of female drivers.

In the analysis, subjects were divided into hypertensive or normotensive groups. We chose to use blood pressure as a dichotomous rather than a continuous variable because of the number of individuals using antihypertensive medication in both the study and comparison populations. Hypertension was defined as: (1) systolic blood pressure greater than or equal to $140 \mathrm{mmHg}$; or (2) diastolic blood pressure greater than or equal to $90 \mathrm{mmHg}$; or (3) current use of antihypertensive medication. These cut-off points for this definition were chosen according to the guidelines recommended by the National Institute of Health (NIH) ${ }^{6}$

All measurements were taken by senior nurses who were unaware of the study hypothesis. At the screening examination, blood pressure was measured after five minutes rest with the subjects seated. Measurements were taken on the right arm using a standard mercury manometer. Overweight may be defined as a body mass index (BMI) between 25 and 30 , obesity may be defined by a BMI above 30 according to recommendations of the WHO. ${ }^{7}$ Hypercholesterolemia and hypertriglyceridemia were defined as $\geq 200 \mathrm{mg} / \mathrm{dl}$ and $\geq 130 \mathrm{mg} / \mathrm{dl}$ respectively according to standard laboratory procedures.

In the analysis, the bus drivers and the skilled workers were divided into six five-year age groups $(30-34,35-39$, $40-44,45-49,50-54,55-59)$. These age groups were chosen becaused they include the entire age range of bus drivers in the study population. Age-specific hypertension rates for bus drivers were calculated and compared with rates calculated for the skilled workers. A likelihood ratio test producing a chi-square statistic was used for testing the difference in risk factors (BMI, hypertension, cholesterol, triglyceride and EKG) between the bus drivers and the skilled workers.

\section{Results}

The number of bus drivers and skilled workers in each age group is shown in Table 1. A total of 1761 bus drivers and 536 skilled workers had sufficient data for inclusion in the analysis. The hypertension rates for the bus drivers and the skilled workers are shown in Table 2.

The hypertension rate for bus drivers was significantly greater than for skilled workers. Chi-square test was used to examine the difference in hypertension prevalence between bus drivers and skilled workers. This difference was statistically significant at the 0.05 level or less when controlling for age. However, there were to be striking differences in the level of this significance with age, with the greatest differences in the 30-34 y age group.

Table 3 compares the risk factors for CHD in bus drivers with those in skilled workers. Significant differences were noted in BMI, serum cholesterol, serum triglyceride and ischemic heart disease. Among bus drivers, the prevalence of obesity was $9.6 \%$, hypercholesterolemia $34.0 \%$, hyper-
Table 1 Number (and percentage) of bus drivers and skilled workers in each age group

\begin{tabular}{lrrrrr}
\hline \multirow{2}{*}{$\begin{array}{c}\text { Age group } \\
\text { (y) }\end{array}$} & \multicolumn{2}{c}{ Bus driver } & & \multicolumn{2}{c}{ Skilled worker } \\
\cline { 2 - 3 } & $n$ & $(\%)$ & & $n$ & $(\%)$ \\
\hline $30-34$ & 27 & $(1.5)$ & 19 & $(3.5)$ \\
$35-39$ & 156 & $(8.9)$ & 81 & $(15.1)$ \\
$40-44$ & 344 & $(19.5)$ & 143 & $(26.7)$ \\
$45-49$ & 560 & $(31.8)$ & 119 & $(22.2)$ \\
$50-54$ & 458 & $(26.0)$ & 90 & $(16.8)$ \\
$55-59$ & 216 & $(12.3)$ & 84 & $(15.7)$ \\
Total & 1761 & $(100.0)$ & 536 & $(100.0)$ \\
\hline
\end{tabular}

Table 2 Prevalence rates of hypertension by age group

\begin{tabular}{lllc}
\hline $\begin{array}{c}\text { Age group } \\
\text { (y) }\end{array}$ & \multicolumn{1}{c}{$\begin{array}{c}\text { Bus driver } \\
\%\end{array}$} & $\begin{array}{c}\text { Skilled worker } \\
\%\end{array}$ & $\begin{array}{c}\text { Chi-square } \\
\text { for } P \text {-value }\end{array}$ \\
\hline $30-34$ & $48.1(13 / 27)$ & $21.1(4 / 19)$ & $<0.01$ \\
$35-39$ & $43.6(68 / 156)$ & $19.8(16 / 81)$ & $<0.01$ \\
$40-44$ & $51.7(178 / 344)$ & $23.8(34 / 143)$ & $<0.01$ \\
$45-49$ & $55.7(312 / 560)$ & $37.0(44 / 119)$ & $<0.05$ \\
$50-54$ & $58.3(267 / 458)$ & $36.7(33 / 90)$ & $<0.05$ \\
$55-59$ & $68.5(148 / 216)$ & $39.3(33 / 84)$ & $<0.05$ \\
Total & $56.0(986 / 1761)$ & $30.6(164 / 536)$ & $<0.05$ \\
\hline
\end{tabular}

triglyceridemia $69.4 \%$ and ischemic heart disease $1.7 \%$. By contrast, among skilled workers, the prevalence of obesity was only $4.6 \%$, hypercholesterolemia $29.9 \%$, hypertriglyceridemia $30.6 \%$ and ischemic heart disease $0.9 \%$.

\section{Discussion}

The present study has described the cross-sectional findings for coronary heart disease risk factors based on data gathered from the records of annual medical examinations for bus drivers and skilled workers conducted at Taipei Municipal Chronic Disease Hospital from July 1998 to June 1999. The results showed a higher prevalence of CHD risk factors in bus drivers, including increased prevalence of high blood pressure, obesity, ischemic heart disease and elevated serum cholesterol and triglycerides. These findings are in agreement with those reported by Hartvig and Midttun, ${ }^{8}$ from a controlled cohort study which compared CHD risk factors among bus drivers and industrial workers in Norway, and found that bus drivers had higher mean values of serum cholesterol, serum triglycerides, systolic and diastolic blood pressure.

Studies in occupational health have traditionally demonstrated the relationship between physical and chemical hazards of the occupational environment and specific disease outcomes, especially cancer of various sites. More recently, there has been increased interest in occupational differences in coronary heart disease. The reasons for the 
Table 3 Risk factors in bus drivers compared to skilled workers in the same company

\begin{tabular}{|c|c|c|c|c|c|}
\hline \multirow[b]{2}{*}{ Risk factor } & \multicolumn{2}{|c|}{$\begin{array}{l}\text { Bus driver } \\
(n=1761)\end{array}$} & \multicolumn{2}{|c|}{$\begin{array}{l}\text { Skilled worker } \\
\quad(n=536)\end{array}$} & \multirow[b]{2}{*}{ Chi-square for $P$-value } \\
\hline & $n$ & $(\%)$ & $n$ & $(\%)$ & \\
\hline \multicolumn{6}{|l|}{ Body mass index (BMI) } \\
\hline$<20$ (underweight) & 67 & (3.8) & 34 & $(6.3)$ & $<0.01$ \\
\hline $20-24.9$ (normal) & 757 & $(43.0)$ & 284 & $(52.5)$ & \\
\hline $25-29.9$ (overweight) & 767 & $(43.6)$ & 198 & $(36.6)$ & \\
\hline$\geq 30$ (obese) & 168 & $(9.6)$ & 25 & $(4.6)$ & \\
\hline \multicolumn{6}{|l|}{ Cholesterol } \\
\hline$<200$ (normal) & 1162 & $(66.0)$ & 380 & $(70.1)$ & $<0.05$ \\
\hline$\geq 200$ (hypercholesterolemia) & 598 & $(34.0)$ & 162 & $(29.9)$ & \\
\hline \multicolumn{6}{|l|}{ Triglyceride } \\
\hline$<130$ (normal) & 941 & $(53.5)$ & 819 & $(46.5)$ & $<0.001$ \\
\hline$\geq 130$ (hypertriglyceridemia) & 376 & $(69.4)$ & 166 & $(30.6)$ & \\
\hline \multicolumn{6}{|l|}{ Electrocardiogram (EKG) } \\
\hline Normal & 1525 & $(86.5)$ & 475 & $(87.8)$ & $<0.01$ \\
\hline Ischemic heart disease & 30 & $(1.7)$ & 5 & $(0.9)$ & \\
\hline Others & 207 & (11.7) & 61 & (11.3) & \\
\hline
\end{tabular}

impact of occupation on coronary heart disease incidence are not well established. One possibility is that psychological or social aspects of the occupation may be involved. During the past several decades, evidence has accumulated regarding the role of psychosocial factors in CHD. ${ }^{9,10}$ For example, individuals who work long hours or have more than one job ${ }^{11,12}$ may be at increased risk for CHD. Likewise, individuals in jobs characterized by overload or excess demands show increased incidence of CHD. ${ }^{13}$ An intriguing conceptualization of findings in this area, advanced by Karasek, ${ }^{14}$ is that jobs which involve excessive psychological or physical workload, and which do not provide adequate resources for dealing with this workload, lead to increased psychological and physical strain, and to a subsequent increased risk of disease.

The occupation of driving a bus in a modern urban transit system particularly exemplifies this pattern. This occupation is characterized by a high level of pressure to perform a complex task under a rigid time schedule, in conjunction with a high level of responsibility for passengers and equipment, and a low level of control or discretion over how this task is conducted. ${ }^{15}$ In addition, driving a bus differs from other occupations along a variety of dimensions, including the level of physical activity, the potential for disruption in diet and sleep habits, and exposure to various elements of the physical environment such as carbon monoxide, lead and noise. These factors may also contribute to the increased health risks experienced by bus drivers. ${ }^{16,17}$

Possible confounding factors related both to occupation and to risk factors (blood pressure, serum lipid, BMI) in this study include most major demographic factors such as age and socio-economic class. We controlled for age by using age-specific comparisons for blood pressure. Social and economic factors were not directly controlled; how- ever, income was not considered a confounding factor since the bus drivers had the same median income as skilled workers in the company. In addition, selection factors which operate on groups of employed individuals contribute to the 'healthy worker effect' in which individuals who are employed will probably be in better health and have lower disease rates than individuals who are not employed. ${ }^{18}$ We controlled for this effect by choosing employed individuals from the same company.

\section{Conclusions}

The evidence presented here shows that bus drivers in Taipei have rates of obesity, hypertension, hypercholesterolemia, hypertriglycerolemia and ischemic heart disease which are significantly higher than comparable groups of skilled workers.

\section{Acknowledgements}

We would like to thank the Tapei Municipal Bus Administrative Bureau for active participation in and support of this project.

\section{References}

1 Rosengren A, Anderson K, Wilhelmsen L. Risk of coronary heart disease in middle-aged male bus and tram drivers compared to men in other occupations: a prospective study. Int J Epidemiol 1991; 20: 82-87.

2 Belkic' $\mathrm{K}$ et al. Determinants of cardiac risk in professional drivers. Kardiologija 1992; 13: 145-149. 
3 Morris $\mathrm{JN}$ et al. Incidence and prediction of ischemic heart disease in London busmen. Lancet 1966; 2: $353-$ 359.

4 Netterstrom B, Laursen P. Incidence and prevalence of ischemic heart disease among urban bus drivers in Copenhagen. Scand J Soc Med 1981; 9: 75-79.

5 Paradis G, Theriault G, Tremblay C. Mortality in a historical cohort of bus drivers. Int J Epidemiol 1989; 18; $397-$ 402.

6 National Institute of Health (NIH). The Sixth Report of the Joint National Committee on Prevention, Detection, Evaluation, and Treatment of High Blood Pressure. National Institute of Health, 1997.

7 Committee on Diet and Health, Food and Nutrition Board. Diet and Health: Implication for Reducing Chronic Disease Risk. National Academy Press: Washington D.C., 1989, pp 99-135.

8 Hartvig P, Midttun O. Coronary heart disease risk factors in bus and truck drivers. Int Arch Occup Environ Health 1983; 52: $353-360$.

9 Feinleib M, Brand RJ, Remington R, Zyzanski SJ. Association of coronary-prone behavior pattern and coronary heart disease. In: Dembrowski TM et al (eds). Coronary Prone Behavior. Springer-Verlag: New York, 1978, pp 2-9.
10 Harburg E et al. Socio-ecological stress, suppressed hostility, skin color and black-white male blood pressure: Detroit. Psychosom Med 1973; 35: 276-296.

11 Theorell T, Rahe R. Behavior and life satisfaction characteristics of Swedish subjects with myocardial infarction. $J$ Chronic Dis 1972; 25: 139-147.

12 House JS. Occupational stress and coronary heart disease: a review and theoretical integration. J Health and Soc Behav 1974; 15: 12-17.

13 French JRP, Caplan RD. Psychological factors in coronary heart disease. Ind Med Surg 1970; 39: 383-397.

14 Karasek $\mathrm{R}$ et al. Job decision latitude, job demands, and cardiovascular disease: A prospective study of Swedish men. Am J Public Health 1981; 71: 694-705.

15 Gardell B, Aronsson G, Barklof K. The working environment for local public transit personnel. Report from the Swedish Work Environment Fund: Stockholm, 1982.

16 Ragland DR et al. Prevalence of hypertension in bus drivers. Int J Epidemiol 1987; 16: 208-214.

17 Talbot E et al. Occupational noise exposure, noise-induced hearing loss, and epidemiology of high blood pressure. Am J Epidemiol 1985; 121: 501-514.

18 McMichael AJ. Standardized mortality ratios and the 'Healthy Worker Effect': scratching beneath the surface. J Occup Med 1976; 128: $165-168$. 